\title{
The diagnosis of pelvic fractures by 'springing'
}

\author{
P. T. GRANT
}

Department of Accident and Emergency Medicine, The University Hospital of South Manchester, and Stockport Infirmary, Cheshire

\section{SUMMARY}

Thirty-six patients were studied prospectively to assess the benefit of 'springing' the pelvis in traumatized patients, to confirrin or refute a fracture of the pelvis None of the patients was multiply injured and half of those with fractures we elderly, sustaining their injuries in simple falls. Springing the pelvis was a poor predictor of the presence or absence of a pelvic fracture, at best it yielded specificity of $71 \%$ and sensitivity of $59 \%$. Its routine use in clinical examination should be abandoned.

\section{INTRODUCTION}

Fractures of the pelvis are commonly seen injuries in our Accident and Emergenctr departments, and are associated with significant morbidity and mortality. Therefore, accurate diagnosis is essential but this can be difficult in a clinical situation: on must have a high index of suspicion of injury especially in the multiply injured patient.

The manoeuvre of 'springing' the pelvis, i.e. applying an alternate compressing and distracting force to the ilia is traditionally taught as the most useful method of detecting such fractures, (Harding et al., 1984; Clain, 1986) and therefore is frequent used in Accident and Emergency departments. It was decided to look at this sigh more closely, in the form of a prospective trial in an attempt to assess its value as $-\mathrm{z}$ discriminator for the presence or absence of a fractured pelvis.

Correspondence: Mr P. T. Grant, Accident and Emergency Department, Western Infirmary, Glasgā G11 6NT, U.K. 


\section{METHODS}

The study was conducted in two Accident and Emergency departments over a 4month period. The attending doctor, who in most cases was a Senior House Officer was asked to complete a brief proforma on any patient he/she intended to X-ray for a possible fracture of the pelvis. Basic patient details were recorded (name, address, date of birth) the cause of the injury (e.g. road traffic accident) and their clinical state on admission, including their Glasgow Coma Scale (GCS) and Trauma Score (TS). All medical staff in both departments were instructed in the standard method of 'springing' the pelvis which is as follows:

(1) Compression: the examiner's hands are placed on either side of the pelvis, just posterior to the anterior superior iliac spine and a medially directed compressing force applied.

(2) Distraction: the hands are placed around and inferior to the anterior superior iliac spine and a postero-lateral synchronous force applied.

The results of each of these manoeuvres were recorded as either positive or negative. The sign was considered positive if the patient produced a painful response verbally, grimaced or via a withdrawal type of movement. Finally the results of pelvic X-ray were recorded and subsequently compared with a formal radiologist's report.

\section{RESULTS}

A total of 49 patients were studied and completed details were available on 36 $(73.4 \%)$. There were 17 males and 19 females, with an age range of 9-95 years. The mean age was 46 years. Of the 36 patients, $22(61 \%)$ were found to have a fractured pelvis radiologically (X-ray positive) and $14(39 \%)$ did not (X-ray negative), although two of this latter group were subsequently shown to have a fractured neck of femur. Of the 22 patients who sustained a pelvic fracture 11 were involved in a road traffic accident and the other half (mainly elderly) fell at home. All but two of the 36 patients had a Glasgow Coma Scale of 14 or better and Trauma Scores were similarily 15 or 16 in 33 patients. Table 1 gives the results of 'springing' in the $14 \mathrm{X}$-ray negative patients and Table 2 does similarily for the $22 \mathrm{X}$-ray positive patients. Table 3 shows the results of predicting a pelvic fracture when both compression and distraction yield a positive response. As can be seen this gave a high false negative rate (16 out of 22 ) resulting in a sensitivity of only $27 \%$. If we then consider the diagnostic accuracy of predicting a fracture in the presence of a positive response to compression or distraction (Table 4) there is some improvement of the false negative rate to a sensitivity of $59 \%$, while specificity has, not surprisingly, decreased from $79 \%$ to $71 \%$.

The net effect of these results can be more clearly seen by considering the Youden index or ' $\mathrm{J}$ ' value (Youden, 1950), which is a measure of the efficiency of a diagnostic test. The nearer ' $\mathrm{J}$ ' is to 1 , the better the test. The highest ' $\mathrm{J}$ ' value 
Table 1. Patient data. X-ray negative.

\begin{tabular}{crlrlll}
\hline Patient No. & Age & Cause & GCS & TS & Compression & Distraction \\
\hline 1 & 47 & RTA(D) & 15 & 16 & Negative & Negative. \\
2 & 20 & RTA(D) & 15 & 16 & Negative & Negative. \\
3 & 84 & Fall(H) & 15 & 16 & Negative & Negative. \\
4 & 23 & RTA(D) & 15 & 16 & Positive & Positive. \\
5 & 74 & RTA(D) & 15 & 16 & Negative & Negative. \\
6 & 12 & RTA(Pas) & 4 & 15 & Negative & Negative. \\
7 & 9 & RTA(Pas) & 15 & 16 & Negative & Negative. \\
8 & 39 & RTA(Pas) & 15 & 16 & Negative & Negative. \\
9 & 12 & RTA(Pas) & 15 & 13 & Negative & Negative. \\
10 & 40 & RTA(D) & 15 & 16 & Positive & Negative. \\
11 & 32 & Fall(W) & 15 & 16 & Negative & Negative. \\
12 & 27 & RTA(Pas) & 15 & 16 & Negative & Negative. \\
13 & 23 & RTA(Ped) & 15 & 16 & Positive & Positive. \\
14 & 17 & Fall(S) & 15 & 16 & Positive & Positive. \\
\hline
\end{tabular}

Note RTA (D) = driver, road traffic accident

RTA (Pas) = passenger, road traffic accident

RTA $($ Ped $)=$ pedestrian, road traffic accident

$\mathrm{H}=$ fall at home

$\mathrm{W}=$ fall at work

$\mathrm{S}=$ fall during a sporting activity

obtained was only 0.3 which clearly shows the poor diagnostic accuracy of peligit springing in relation to presence or absence of a pelvic fracture.

\section{DISCUSSION}

Early diagnosis of pelvic fracture is vital to the subsequent outcome of the patien $\overrightarrow{\vec{e}}$ In one study (Rothenberger et al., 1978) of 26 patients who died primarily of pelvie fracture 18 died of exsanguination in the first $9 \mathrm{~h}$. Morbidity can also be considerable with such long term complications as urethral stricture and chronic hip pain. It is now considered standard practice to obtain a pelvic film as part of the routine 'work-up' of the multiply injured patient (Jorden, 1983) since clinical diagnosis of fracture can be so difficult in such patients; but as can be seen from this study has of our patients were elderly and fell at home and indeed of all our patients onle two had a trauma score of 13 (i.e. an approximate mortality rate of $10 \%$, seg Champion, 1981).

Our patients in this study therefore, were not in the multiply injured categor and yet the accuracy of pelvic 'springing' was still poor. It has been suggested (Carter, 1981) that a fractured hip or pelvis may be detected by tapping eachy patella in turn and auscultating at the symphysis pubis in an attempt to detect difference in sound transmission between the two sides, but this is unreliable especially in the presence of, for example, a knee joint effusion, or fractures around the symphysis itself (Sotos, 1983). 
Table 2. Patient Data X-ray positive.

\begin{tabular}{cclrrlll}
\hline Patient No. & Age & Cause & GCS & TS & Compression & Distraction & Fracture \\
\hline 15 & 79 & Fall(H) & 15 & 16 & Negative. & Negative. & I.P.R. \\
16 & 95 & Fall(H) & 15 & 16 & Negative. & Positive. & I.P.R./N. of F \\
17 & 83 & Fall(H) & 15 & 16 & Negative. & Positive. & S.P.R. \\
18 & 30 & RTA(D) & 15 & 13 & Negative. & Negative. & Ilium. \\
19 & 81 & Fall(H) & 15 & 16 & Positive. & Negative. & I.P.R. \\
20 & 21 & RTA(Ped) & 15 & 16 & Negative. & Negative. & I.P.R./N. of F \\
21 & 87 & RTA(Ped) & 14 & 16 & Negative. & Negative. & S.P.R. \\
22 & 83 & Fall(H) & 15 & 16 & Positive. & Negative. & S.P.R. \\
23 & 12 & RTA(Ped) & 14 & 16 & Negative. & Negative. & I.P.R. \\
24 & 86 & Fall(H) & 15 & 16 & Positive. & Positive. & S.P.R. \\
25 & 82 & Fall(H) & 15 & 16 & Positive. & Positive. & S./I.P.R. \\
26 & 38 & RTA(D) & 15 & 16 & Negative. & Negative. & Diast.P.Sym. \\
27 & 20 & RTA(Pas) & 15 & 16 & Positive. & Negative. & S./I.P.R. \\
28 & 17 & RTA(Ped) & 5 & 13 & Negative. & Negative. & S.P.R. \\
29 & 69 & Fall(H) & 15 & 16 & Negative. & Negative. & Acetab./I.P.R. \\
30 & 88 & Fall(H) & 14 & 16 & Negative. & Positive. & S.P.R. \\
31 & 20 & RTA(Ped) & 15 & 15 & Positive. & Positive. & S.P.R. \\
32 & 43 & RTA(D) & 15 & 16 & Positive. & Positive. & S/I.P.R./S.I. \\
33 & 64 & Fall(H) & 15 & 16 & Positive. & Positive. & I.P.R./N. of F \\
34 & 77 & Fall(H) & 13 & 16 & Negative. & Positive. & I.P.R. \\
35 & 12 & RTA(Ped) & 13 & 15 & Positive. & Positive. & I.P.R. \\
36 & 16 & RTA(Pas) & 15 & 16 & Negative. & Negative. & I.P.R. \\
\hline
\end{tabular}

Note RTA (D) = driver, road traffic accident

I.P.R. = Inferior pubic ramus

RTA (Pas) = passenger, road traffic accident

S.P.R. = Superior pubic ramus

RTA $($ Ped $)=$ pedestrian, road traffic accident

N. of F. = Neck of femur

$\mathrm{H}=$ fall at home

S.I.J. = Sacro-clial joint

$\mathrm{W}=$ fall at work

$\mathrm{S}=$ fall during a sporting activity

Acetab. $=$ Acetabunum

Diast.P.Sym. $=$ Diastasis of pubis symphysis

Table 3. Criterion for a fracture: both compression and distraction positive.

\begin{tabular}{|c|c|c|c|}
\hline & Both positive & Other result & Total \\
\hline$X$-ray +ve & 6 & 16 & 22 \\
\hline X-ray -ve & 3 & 11 & 14 \\
\hline \multicolumn{4}{|c|}{$\begin{array}{l}\text { Probability of false positive }=0.21=\text { Specificity } 79 \% \text {. } \\
\text { Probability of false negative }=0.73=\text { Sensitivity } 27 \% \text { 'J' point } 0.0584 \text {. }\end{array}$} \\
\hline $\begin{array}{l}\text { Table } 4 . \\
\text { positive. }\end{array}$ & One positive & Other result & Total \\
\hline X-ray +ve & 13 & 9 & 22 \\
\hline X-ray & 4 & 10 & 14 \\
\hline
\end{tabular}

Probability of a false positive $0.29=$ specificity $71 \%$.

Probability of a false negative $0.41=$ sensitivity $59 \%$ ' $\mathrm{J}$ ' point 0.305 
I would suggest that there is no easy answer to the best method of detecting $\frac{\mathbb{D}}{0}$ these fractures clinically and one must resort to the use of X-rays liberally, not just 3 in major injury but also in the more minor, especially elderly patient who may? only have vague groin discomfort or a mild limp following relatively trivial trauma. $\overrightarrow{\vec{*}}$ I feel that 'springing' the pelvis should no longer be taught to medical studentsand junior doctors alike, and should be completely discarded from our clinical practice.

\section{ACKNOWLEDGEMENTS}

The author would like to thank Mr A. D. Redmond of the University Hospital of South Manchester, and Mr A. J. Gray of Stockport Infirmary for permission to. report on their patients and the junior medical staff of both departments for their help in collecting the data.

\section{REFERENCES}

Carter M. C. (1981) A reliable sign of fracture of the hip or pelvis. New England Journal of Medicine 305 (20), 1220.

Champion H. R., Sacco W. J. \& Carnazzo A. J. (1981) Trauma Score. Critical Care Medicine (9) 672-6. Ф્(

Clain A. (1986) Hamilton Bailey's Demonstration of Physical Signs in Clinical Surgery. J. Wright \& Sors, Bristol. pp. 338

Harding Rains A. J. \& Ritchie H. D. (1984) Bailey \& Love's Short Practice of Surgery. H. K. Lewis \& C\& London. pp. 228

Jorden R. C. (1983) Emergency Medicine Concepts and Clinical Practice. C. V. Mosby Co. Toronto. pp. 126 Rothenberger D. A., Fisher R. P., Velasco R. \& Perry J. F. Jnr. (1978) The Mortality associated with Pelvic Fractures. Surgery 84, 356-61.

Sotos J. G. (1983) Diagnosis of Fractures of the Hip or Pelvis. New England Journal of Medicine 308 (16), 971.

Youden W. J. (1950) Index for rating diagnostic tests. 3, 32-5. 